\title{
Study of a Portable Experimental Set for the Monitoring of lonizing Radiation in the Tropical Region of Brazil
}

\author{
Inácio Malmonge Martin, Marcelo Pego Gomes, Rodrigo Rezende Fernandes de Carvalho and Rafael Gomes \\ Physics Department, Technological Institute of Aeronautics-ITA, São José dos Campos, SP 12228-900, Brazil
}

\begin{abstract}
The Geiger is a proportional counter that detects the ambient ionizing radiation using a sensor tube and an associated electronics that allows feeding the desired voltage to the tube and acquiring the data in a certain time interval. With a sensor tube of Chinese and Russian origin and associated electronics based on the Arduino system, an experimental set of very low cost and easy handling for the monitoring of the local environmental ionizing radiation was set up. The main objective of this work is to disseminate this very low cost technique for the environmental study in secondary schools in Brazil.
\end{abstract}

Key words: Ionizing radiation, environmental study, gamma radiation measurements.

\section{Introduction}

The low energy ionizing radiation $(\alpha, \beta, \mathrm{X}$ and gamma rays) in local environment depends on the presence of radionuclides and radon gas in the region. The local geological formation, the primary and secondary cosmic radiation and human activities improve these radiations in the environment. These radiations with enough energy $(\mathrm{E}>12 \mathrm{eV})$ can ionize an atom. The ionizing radiations have one "background" or background radiation in a particular region that is the sum of these components. The geological origin radiation is largely the result of the decay of radioactive isotopes potassium $\left({ }^{40} \mathrm{~K}\right)$, uranium $\left({ }^{238} \mathrm{U}\right)$ and thorium $\left({ }^{232} \mathrm{Th}\right)$ decay series [1]. The radioactive decay, the cores can emit alpha radiation, beta, gamma or X-rays. Moreover, they are formed natural radioactive isotopes belonging to each decay series mentioned. The ${ }^{235} \mathrm{U}$ has a half-life of 713 million years while the ${ }^{238} U$ has a half-life of 4.5 billion years. With this, there is in nature a much smaller amount of ${ }^{235} \mathrm{U}$ comparing to ${ }^{238} \mathrm{U}$ [2-4].

The other major source of ionizing radiation in the soil-air interface is radon gas $\left({ }^{222} \mathrm{Rn}\right)$ from which is

Corresponding author: Inácio Malmonge Martin, Ph.D., main research fields: ionization radiation, solar physics and earth atmosphere. formed by the decay of uranium and thorium. In turn, the radioactive decay of radon produces ${ }^{218} \mathrm{Po},{ }^{214} \mathrm{~Pb}$ and ${ }^{214} \mathrm{Bi}$, and these isotopes can be observed in the air near the ground by the presence of alpha particles, $\mathrm{X}$ and gamma. An important fact related to radon is that during rain, the concentration close to the ground may increase due to transportation of this gas by rain droplets $[5,6]$.

The radiation from the cosmic component (primary and secondary) produced in the lower atmosphere varies little over time. However, it varies greatly with latitude and height above the Earth's surface [7]. This cosmic radiation produces "extensive showers" composed of particles and energy photons that reach the Earth's surface. Artificial ionizing radiations are those produced by humans in a variety of activities such as medicine, dentistry and research in the industry. However, the sources of radiation are, in principle, confined and under control at a specific location [8, 9].

\section{Material and Methods}

The basic part of the detector is a Geiger built in the laboratory of Atmospheric and Solar Physics Moscow (Dolgaproudny), Russia. It was used tube CTC-6 of 16 $\mathrm{cm}$ long by $2 \mathrm{~cm}$ in diameter with 3 atmospheres of internal pressure and subjected to a voltage of 500 
VDC (Voltage Direct Current). The same Chinese tube J305 from RadiationD-v1.1 (CAJOE Electronics Co., Ltd.) in China of $8 \mathrm{~cm}$ long to $1.3 \mathrm{~cm}$ of diameter with 5 atmospheres internal pressure and with 400-500 VDC (Fig. 1). The electronics associated with the sensor tubes consist of a power supply from 5 VDC to 500 VDC with enough voltage stability. This source is intended to power the Geiger tubes with exactly the same $500 \mathrm{VDC}$ voltage. Another important segment of the circuit is to transform the analog signals from the Geiger sensor into digital signals to acquire these signals as a function of time with minimum accuracy of seconds. In this work, the minimum time of 1 minute was chosen to carry out the time series related to the monitoring of the local ionizing radiation.

In Fig. 2, a block diagram of the feed and acquisition circuit used in this experiment is described.

\subsection{System 1 and System 2}

In relation to system 1, a $5 \mathrm{~V}$ voltage is supplied via a USB/Serial cable and the code upload for Arduino board (Model UNO R3) by the computer. Arduino board provides a $5 \mathrm{~V}$ ddp ( $5 \mathrm{~V}$ and $0 \mathrm{~V}$ GND Pins) to the radiation detection system. The detection system feeds the Russian tube with a voltage ranging from 0 to $600 \mathrm{~V}$ (nominal values). The Russian tube, when it detects radiations, gamma or beta, emits pulses for the radiation detection system which then sends them to the arduino (digital pin 2) converting them into digital data. These are sent and stored on the PC. The same process occurs with System 2, but unlike System 1, the Chinese Geiger J3058 is one of the components that make up the radiation detection system.

\section{Results}

The measurements were carried out in a closed room with air conditioning in $20{ }^{\circ} \mathrm{C}$ in the Laboratory of Electricity and Magnetism of the Department of Physics of ITA (Technological Institute of Aeronautics), in São José dos Campos, SP, Brazil. Detector and associated electronics were previously calibrated in ITA laboratory using radioactive sources Cs-137, Sr-90

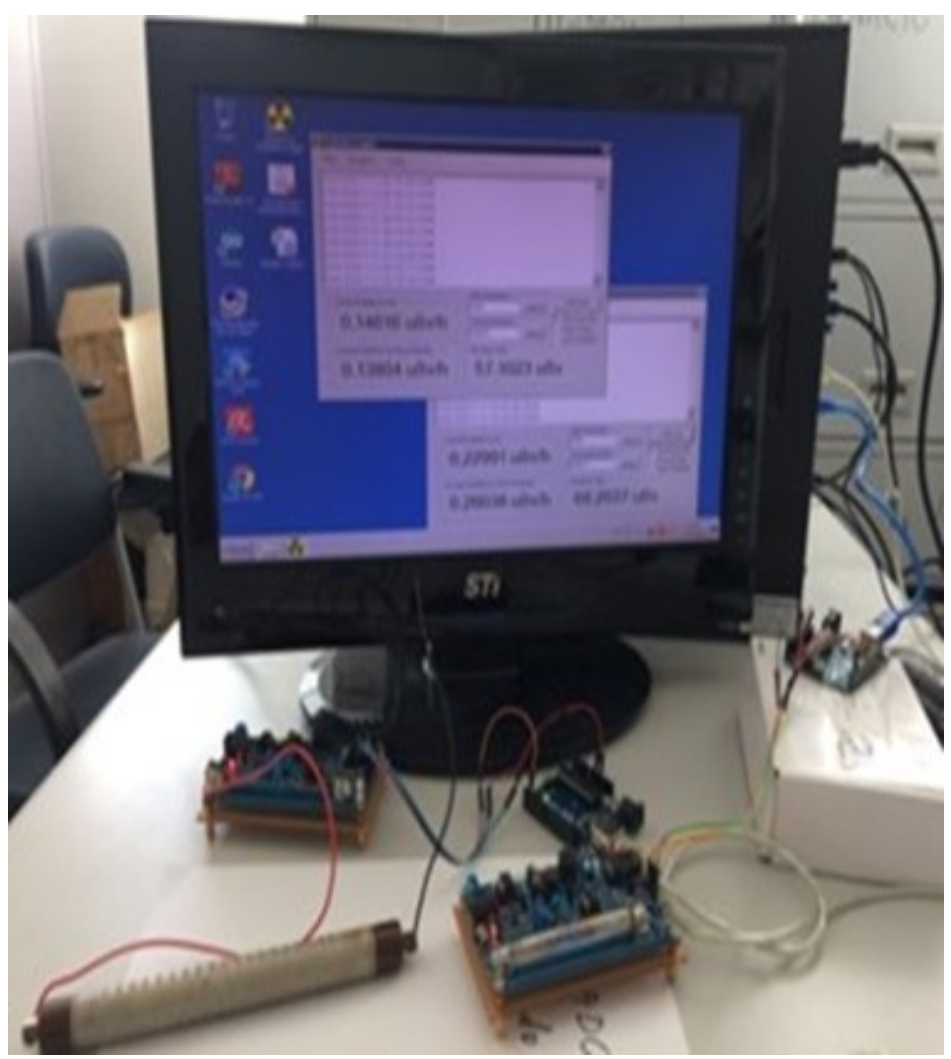

Fig. 1 Tubes (Russian and Chinese) with Arduino electronics and data acquisition with PC. 


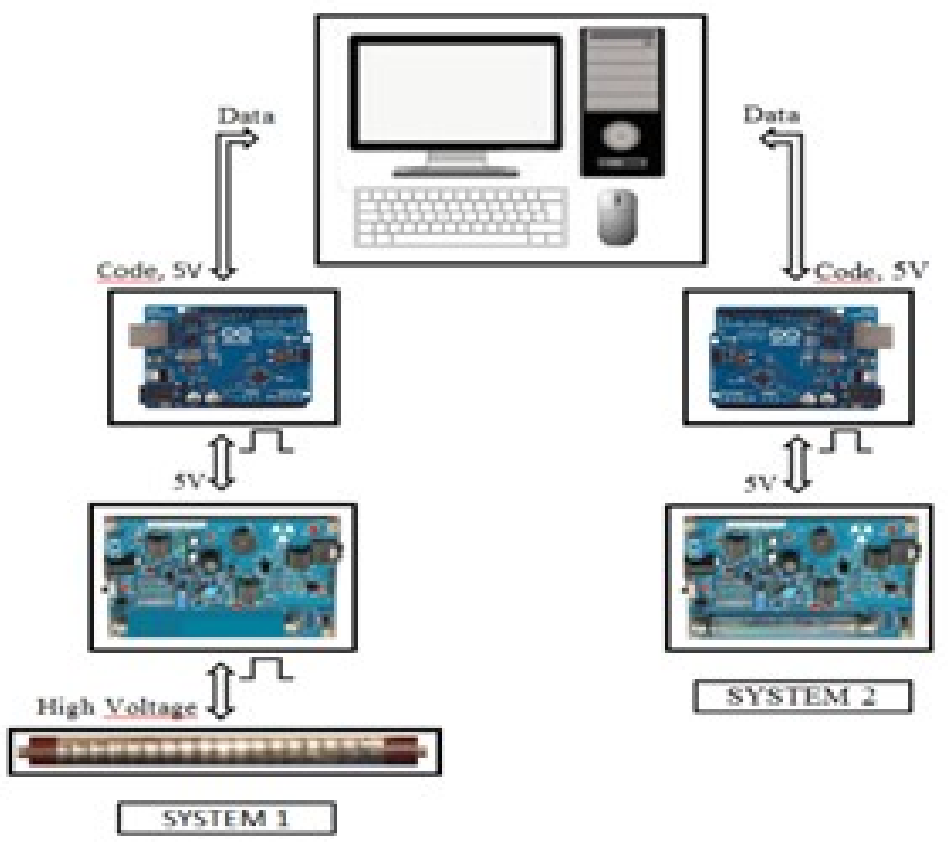

Fig. 2 Schematic of the detector tube and an associated electronics.

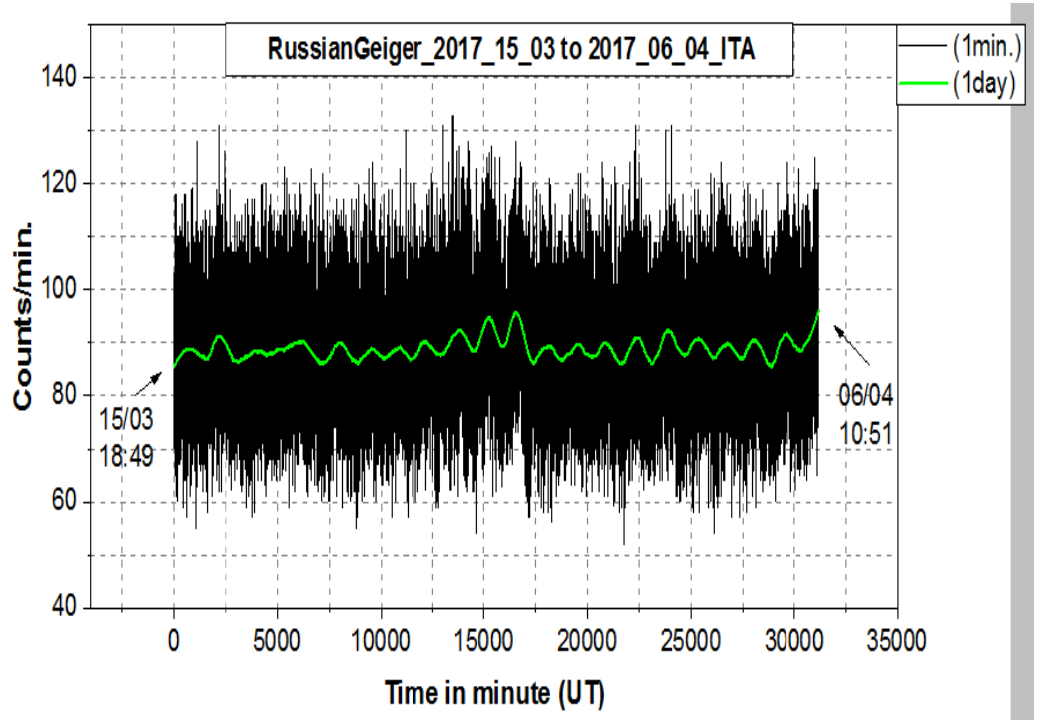

Fig. 3 Measurements of variation of environmental ionizing with Russian Geiger.

and Po-210 in terms of energy from emitted photons and particles: $1.17 \mathrm{MeV}, 0.90 \mathrm{MeV}$ and $5.4 \mathrm{MeV}$ respectively [9].

Between the March 15 to April 6 of 2017, the uninterrupted monitoring of the local environmental ionizing radiation was carried out simultaneously with Russian Geiger and China Geiger. The variation of the ambient ionizing radiation measured over the whole period is shown in Fig. 3. Between 5,000-6,500 minutes from the start of monitoring, the radiation intensity does not show day/night variation. This is due to continuous rains in this period as shown in Fig. 5. Between the time 7,000 to 31,000 minutes, there were no rains in the region only two drizzles and the presence of low cumulus clouds that also interfere in the greater or lesser intensity of environmental ionizing radiation. This condition always exhibits a variation of day/night that also interferes in the greater or lesser intensity of environmental ionizing radiation. 


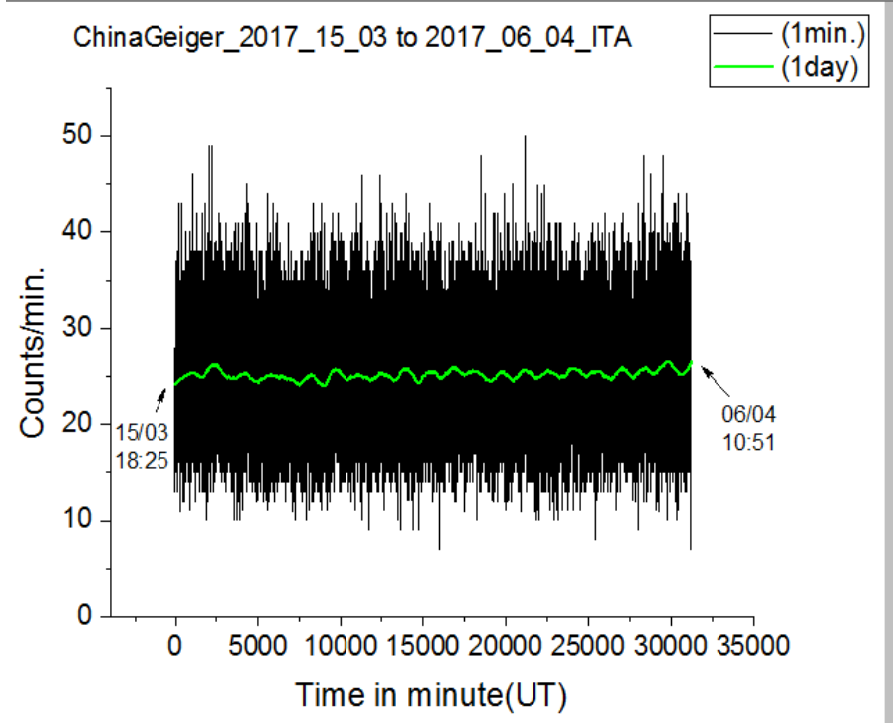

Fig. 4 Measures carried out in the same period and place with China Geiger.

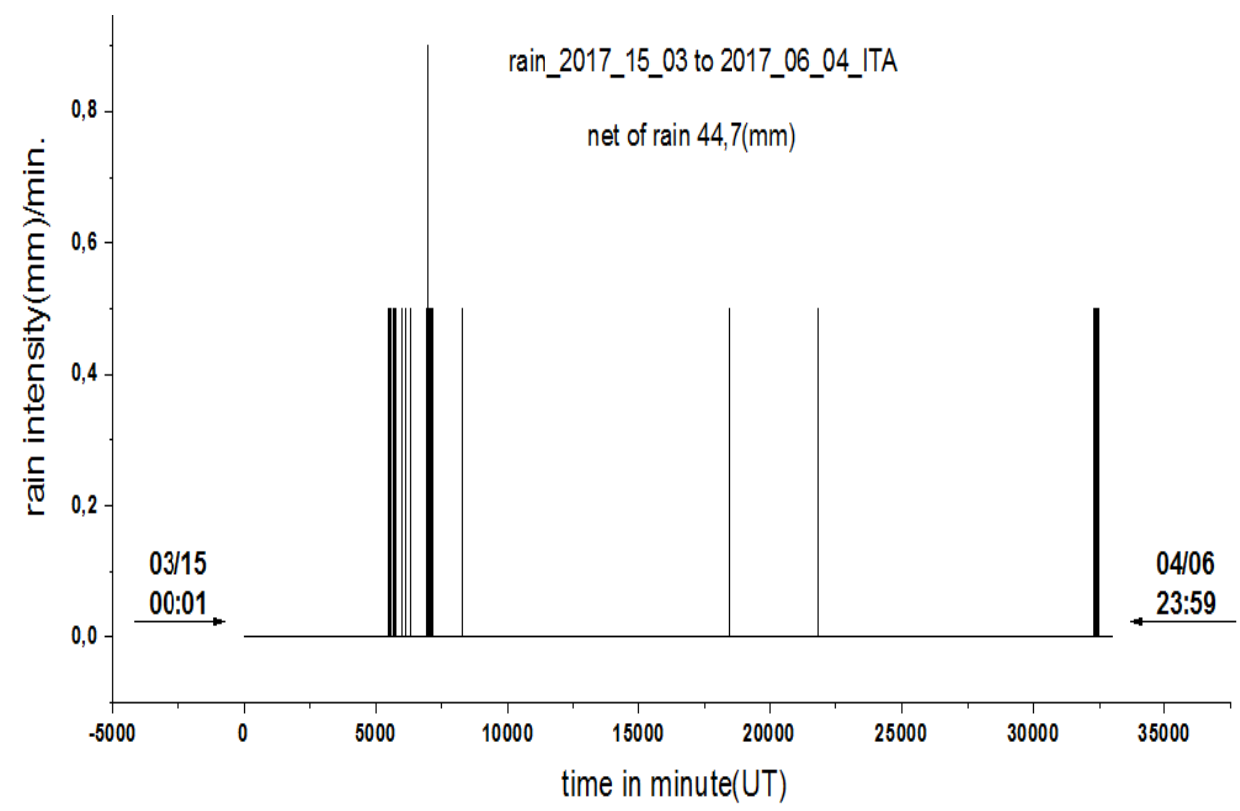

Fig. 5 Measurements of rainfall variation in $(\mathrm{mm} / \mathrm{min})$ in the period 03/15 to 04/06 of 2017 .

It can be seen in Fig. 4 that the China Geiger detector exhibits lower performance than Russian Geiger, this being due to being smaller in sensitive area and being the glass sensor tube. Comparing the walls of the tubes, the one manufactured by Russians is thinner than the Chinese, allowing more entrances of particles and photons. However, as shown in Fig. 4, the Chinese tube also shows dry periods and rainfall in the region.

In Fig. 5, it is shown monitoring, also at each minute, the variation of the rain intensity in $(\mathrm{mm} / \mathrm{min}$.) at the same location of the Geiger detectors.

It is observed that between 5,000 and 6,500 minutes of measurements rainfall was present at the monitoring site. Considering all the period, a total of $44.7 \mathrm{~mm}$ of rainfall was measured at the site. It can be affirmed observing the measurements made and described in Figs. 3-5 that the variations of the local environmental ionizing radiation is related to the presence of the rains and the greater or less insolation of the place due to clouds. 


\section{Conclusion}

Thinking about the teaching and ionizing radiation (environmental) in the Brazilian tropical region and secondary school education, two Geiger Sensors with Sensitive Tubes manufactured in Russia and China were developed. The associated electronics based on the Arduino system, presents very low cost, easy operation with data acquisition and can vary from seconds to hours of interval of measurements. Analog signals from digital-switched detectors are recorded and saved in easy-to-use graphical (txt) files by secondary students. It was shown to be very sensitive and proven good functionality during the period from March 15 to April 6, 2017. It was observed during this period the variation (night/day) produced in the place by the exhalation of radon gas $(\mathrm{Rn}-222)$. This gas through decay produces gamma rays and alpha particles responsible for the observed variation (day/night) and during rains. It lends itself to secondary education and in the first two years of the Brazilian universities as suggested experiments of laboratory of exact sciences and of the Earth, given the low cost and very simple operation.

\section{Acknowledgment}

Thanks to CNPq (National Counsel of Technological and Scientific Development) and CAPES (Coordination for the Improvement of Higher Education Personnel) by the fellowships grants support to the group's researchers and the ITA Division of Fundamental Sciences for supporting this research.

\section{References}

[1] Grieder, P. K. 2010. Extensive Air Showers (Vol. 1). Springer: Verlag.
[2] Bui-Van, N. A., Martin, I. M., and Turtelli Júnior, A. 1988. "Measurements of Natural Radioactivity at Different Atmospheric Depths." Ciencia e Cultura. Suplemento 40 (7): 407.

[3] Fujinami, N. 2009. "Study of Radon Progeny Distribution and Radiation Dose Rate in the Atmosphere." Japanese Journal of Health Physics 44 (1): 89-94.

[4] Martin, I. M., Gusev, A. A., Santos, T. A., and Sismanoglu, B. N. 2015. "Radon Gas and Increasing Intensity of Gamma Radiation near Ground Level Interface on 2011 in Sao Jose dos Campos, SP, Brazil.” International Journal of Research in Engineering \& Technology 3: 31-8.

[5] Martin, I. M., Alves, M. A., Gomes, M. P., Ferro, M. A., Pinto, M. L., and Antônio, F. C. 2013. "Measurements of $\mathrm{X}$ and Gamma Radiation at Ground Level and Their Correlation with Atmospheric Electric Discharges and Rainfall in São José dos Campos, SP, Brazil.” In 13th International Congress of the Brazilian Geophysical Society \& EXPOGEF, Rio de Janeiro, Brazil, 26-29 August 2013: 272-4. Society of Exploration Geophysicists and Brazilian Geophysical Society.

[6] Jayanthi, U. B., Gusev, A. A., Neri, J. A. C. F., Villela, T., Pinto Júnior, O., Pugacheva, G. I., et al. 2005. "Ground Gamma Radiation Associated with Lightning and Rain Precipitation.” In International Cosmic Ray Conference 1: 117. Pune, India.

[7] Babich, L. P., Bochkov, E. I., Kutsyk, I. M., and Rassoul, H. K. 2014. "Analysis of Fundamental Interactions Capable of Producing Neutrons in Thunderstorms." Physical Review D 89 (9): 093010.

[8] Boardman, B. J. 2015. “Aware Electronic Corp.” Accessd May 1, 2017. http://www.aw-el.com/users.html.

[9] Martin, I. M., Germano, J. S. E., and Takaki, T. M. 2013. "ITA-DATALOGGER: Continuous Monitoring of Pressure, Relative Humidity, Temperature, Rainfall Intensity and Dose of Ionizing Radiation near the Surface of the Earth in São José dos Campos, SP, Brazil." Presented at 65th Annual Meeting of Brazilian Science for Progress Society (SBPC), Recife, Brazil.

[10] Gusev, A. A., Martin, I. M., Alves, M. A., and de Abreu, A. J. 2015. "Simulation of the Radiation Fallout from Gamma-Ray Measurements." Modeling Earth Systems and Environment 1 (3): 18. 